\title{
Relação entre Distribuição de Rendimentos do Trabalho e Industrialização: uma Análise para os Municípios Brasileiros*
}

\section{Labor Income Distribution and Industrialization: Evidences from Brazilian Municipalities}

\author{
Bruno Benzaquen Perosa ${ }^{\mathrm{a}}$ \\ Carlos César Santejo Saiani ${ }^{\mathrm{a}}$ \\ Patrick Leite Santos ${ }^{\mathrm{a}}$
}

\begin{abstract}
Resumo: O presente estudo investiga, empiricamente, a relação entre industrialização e distribuição dos rendimentos do trabalho nos municípios brasileiros. Com base em debates históricos sobre distribuição de renda da academia brasileira e em hipóteses associadas à curva de Kuznets, especialmente, a que se refere à economia dual, o estudo encontra uma relação não linear entre a desigualdade de rendimentos do trabalho e a industrialização, medida pelas participações industriais no produto e no emprego. A partir de dados municipais referentes a 2000 e 2010, são realizadas regressões paramétricas em painel (efeitos fixos, efeitos aleatórios e tobit) e não paramétricas (kernel-weighted local polynomial regression). As evidências, relativamente robustas, sugerem que a curva derivada da relação entre a desigualdade de renda e a industrialização tem um formato próximo a um $U$ invertido. Ou seja, a distribuição dos rendimentos do trabalho piora com a industrialização até certo nível de participação industrial (no produto e no emprego), porém, atingido determinado nível, a distribuição passa a melhorar.
\end{abstract}

Palavras-chave: Industrialização. Distribuição de renda. Curva de Kuznets. Dados em painel.

\begin{abstract}
This paper presented an empirical investigation of the relation between industrialization and labor income on Brazilian municipalities. Based on the Brazilian debates on income distribution and Kuznets curve, specially the dual economy hypotheses, this research found a nonlinear relation between labor income inequality and industrialization, here considered as the share of industrial sector on product and jobs. Considering municipal data from 2000 to 2010, parametric (fixed effects, random effects and Tobit) and nonparametric (Kernel-Weighted Local Polynomial Regression) regressions offered relatively robust evidence suggesting that the curve relating inequality and industrialization has a "U-inverted" shape. In conclusion, labor income distribution is aggravated (reduced) when the industrial sector increases its share (on both the product and jobs), but, after a certain level, the distribution starts to get better.
\end{abstract}

\footnotetext{
* Os autores agradecem o apoio financeiro da FAPEMIG e do CNPq.

a Universidade Federal de Uberlândia (UFU), Instituto de Economia e Relações Internacionais (IERI). Uberlândia, Minas Gerais, Brasil.
} 
Keywords: Industrialization. Income distribution. Curve of Kuznets. Panel data.

JEL Classification: O14; O15; R11.

\section{Introdução}

Distribuição de renda e industrialização são importantes questões no debate econômico. No cenário acadêmico, as duas temáticas são relacionadas por diferentes abordagens. No Brasil, destaca-se o debate que ficou conhecido como "controvérsia de 70", no qual diferentes vertentes tentaram explicar o aparente caráter concentrador de renda do crescimento econômico impulsionado pela industrialização do período do "Milagre Econômico" no governo militar. Em âmbito mundial, interações entre crescimento econômico, industrialização e desigualdade de renda são discutidas por diferentes teorias, destacando-se a da Curva de Kuznets (CK).

A hipótese da CK pressupõe uma relação no formato próximo a um " $U$ invertido" entre a desigualdade de renda e o crescimento econômico. Ou seja, em níveis baixos de renda per capita, a desigualdade de renda aumentaria em função do crescimento; porém, atingido certo nível de renda (turning point), a desigualdade passaria a cair (KUZNETS, 1955; DEUTSCH; SILBER, 2000). Tal hipótese embasa, inclusive, argumentos da "controvérsia de 70". Diversos trabalhos contestam a CK, defendendo que a desigualdade de renda teria dinâmica cíclica associada ao crescimento econômico. Dentre esses trabalhos, deve-se destacar aqueles que preconizam uma relação desigualdade-crescimento em formato de um " $N$ ": ou seja, a desigualdade voltaria a aumentar em maiores níveis de renda (LIST; GALLET, 1999).

A relação desigualdade-crescimento nos formatos da $\mathrm{CK}$ ou do $N$ é justificada por vários aspectos, dentre os quais, argumentos associados à abordagem da economia dual, para a qual a desigualdade de renda seria influenciada pelo perfil setorial da economia. $\mathrm{O}$ aumento e a posterior queda da desigualdade de renda em função do crescimento econômico decorreriam da transição de uma economia baseada em atividades de agropecuária para uma economia com predominância industrial - industrialização. A migração de trabalhadores e os diferenciais de produtividade do trabalho e de rendimentos entre os setores gerariam, no início, aumento da desigualdade, mas, com a consolidação da indústria, a desigualdade diminuiria. Em um segundo momento, a transição de uma economia industrial para uma com maior relevância dos serviços - o que, segundo Clark (1957) e Rowthorn e Ramaswamy (1997), pode sinalizar uma desindustrialização natural - aumentaria a desigualdade de renda devido à migração de trabalhadores e aos diferenciais de produtividade e rendimentos entre os setores (KUZNETS, 1995; BISHOP; FORMBY; THISTLE, 1991; LIST; GALLET, 1999). 
Com base nesses debates, este estudo investiga, empiricamente, como a industrialização afeta a desigualdade da distribuição pessoal dos rendimentos do trabalho nos municípios brasileiros. Especificamente, é averiguado se as relações entre a desigualdade de rendimentos e as participações industriais no produto e no emprego não são lineares, apresentando formato próximo a um $U$ invertido. Ou seja, se a desigualdade de renda aumenta em função da industrialização em níveis baixos de participações industriais e passa a diminuir quando são atingidas certas participações (turning points). Tal hipótese é embasada pelas citadas discussões da abordagem da economia dual. Além disso, as hipóteses da CK e do $N$ também são testadas para os municípios brasileiros.

É importante ressalvar que os impactos da industrialização sobre a desigualdade de renda de um local decorrem de efeitos de composição e de concentração (SOARES, 2006; HOFFMANN; NEY, 2008). O primeiro é a variação da desigualdade provocada por alterações da participação industrial na economia. O segundo é a variação da desigualdade por mudanças da concentração de renda na indústria. Evidências de Marconi (1997), Belluzzo, Anuatti Neto e Pazello (2005), Hoffmann (2011) e Oliveira e Silveira Neto (2016), com análises estáticas, sinalizam que a indústria, em comparação aos outros grandes setores econômicos, concentra menos renda no Brasil.

Assim, se ocorresse apenas um efeito composição, o aumento da participação industrial deveria sempre resultar em menor desigualdade de rendimentos do trabalho nos municípios brasileiros. Porém, se for constatada a relação não linear, pode-se inferir que a industrialização impacta sobre a desigualdade dos rendimentos do trabalho por combinações dinâmicas dos efeitos de composição e de concentração, o que corroboraria argumentos da economia dual.

Para se testar as hipóteses, são realizadas estimações paramétricas em painel (efeitos fixos, efeitos aleatórios e tobit) e não paramétricas (kernel-weighted local polynomial regression) para todos os municípios brasileiros, com dados disponibilizados referentes aos anos de 2000 e 2010. Os dados são oriundos do Instituto Brasileiro de Geografia e Estatística (IBGE) e do Programa das Nações Unidas para o Desenvolvimento (Pnud). Como medida de desigualdade de renda, é usado o índice Theil- $L$ dos rendimentos do trabalho. Seguindo Rowthorn e Wells (1987), Rowthorn e Ramaswamy (1997) e Tregenna (2009), são adotadas duas medidas de (des)industrialização: a participação do valor adicionado (VA) pela indústria no PIB; e participação industrial no emprego. Já como medida de renda per capita, é utilizado o PIB per capita.

Deve-se ressaltar que, ao considerar um indicador de desigualdade dos rendimentos do trabalho, o presente estudo também se insere no debate sobre a distribuição pessoal (e setorial) da renda no Brasil. A distribuição pessoal é uma das categorias que compõem a distribuição funcional da renda. $\mathrm{O}$ termo pessoal é utilizado para referir-se especificamente aos rendimentos do trabalho. Já o termo funcional 
é mais abrangente, pois objetiva captar a função de todos os agentes econômicos envolvidos no processo produtivo, tanto pelos rendimentos do trabalho - pessoal quanto pelos rendimentos do capital - juros e lucros - e da propriedade - aluguéis, por exemplo. Segundo dados das Contas Nacionais do Brasil, a participação dos rendimentos do trabalho na renda total do país em 2000 e 2010 - ou seja, nos anos analisados no presente estudo -, era de 40\% e 43\%, respectivamente (INSTITUTO DE PESQUISA ECONÔMICA APLICADA, 2010; HALLAK NETO; SABOIA, 2014).

Antecipadamente, deve-se apontar que as evidências encontradas não refutam a hipótese derivada da economia dual de que a relação desigualdade-industrialização tem, nos municípios brasileiros, um formato próximo a um $U$ invertido, tanto para a participação industrial no produto quanto no emprego. Assim, a desigualdade dos rendimentos do trabalho aumenta com a industrialização até certas participações da indústria, a partir das quais cai. A não linearidade das relações obtidas sugere que o impacto da indústria na desigualdade de rendimentos não advém apenas de um efeito composição, mas da combinação deste com um efeito concentração.

As evidências aqui encontradas contribuem, por um lado, preenchendo uma lacuna na literatura empírica, ao menos para os municípios brasileiros, pois poucos trabalhos averiguaram explicitamente a relação desigualdade-industrialização ao invés da desigualdade-crescimento nos formatos da $\mathrm{CK}$ ou $\mathrm{N}$, e utilizam a economia dual apenas como possível explicação. ${ }^{1}$ Por outro lado, garantem evidências adicionais à literatura sobre consequências favoráveis da industrialização, que enfatiza impactos no crescimento econômico: a) efeitos de encadeamento nas cadeias produtivas; b) produtividade industrial crescente em função da produção do setor; c) indução e difusão de progresso tecnológico; e d) elasticidades-renda das importações de bens industriais superiores às de commodities e primários, aliviando o balanço de pagamentos. ${ }^{2}$

O presente estudo está estruturado em mais quatro seções, além desta introdução. Na segunda seção, é realizada uma breve revisão da literatura sobre os possíveis efeitos da industrialização sobre a desigualdade de renda, destacando debates da academia brasileira e em âmbito mundial que fundamentam as hipóteses da abordagem da economia dual. Na terceira seção, são apresentadas as estratégias empíricas (baseadas em estimações econométricas em painel) utilizadas para testar as hipóteses e, assim, verificar como a industrialização afeta a desigualdade da distribuição pessoal do trabalho nos municípios brasileiros. Na quarta seção, são analisados os resultados obtidos por meio das estratégias empíricas propostas. Por fim, são apresentadas as considerações finais do estudo.

$1 \quad$ Na verdade, foi encontrado apenas o trabalho de Bêrni, Marquetti e Kloeckner (2002), que testa, somente para municípios do estado do Rio Grande do Sul, a hipótese da CK substituindo a medida de renda per capita pelo valor adicionado da indústria, mas não sua participação no produto e nem a participação industrial no emprego.

2 Para mais detalhes, conferir, por exemplo, Kaldor (1966) e Oreiro e Feijó (2010). 


\section{Referencial Histórico, Teórico e Empírico}

De forma a trazer maior sustentação às análises empíricas deste trabalho, a presente seção apresenta uma breve revisão bibliográfica, considerando estudos teóricos e empíricos, sobre possíveis relações entre distribuição de renda e industrialização. É dada maior ênfase a debates nacionais e internacionais que embasam a abordagem da economia dual, que fundamenta este estudo.

\subsection{Debates sobre a Industrialização e a Distribuição de Renda no Brasil}

O processo de industrialização brasileiro iniciado na década de 1930, no governo do presidente Getúlio Vargas, contou com atuação direta do Estado. Tal indução estatal encontra na literatura várias justificativas, desde trabalhos que a entendiam como uma forma de proteção e diversificação do capital cafeeiro, embasados no livro de Celso Furtado, Formação econômica do Brasil (FURTADO, 1967), até trabalhos que defendiam mudança na estrutura produtiva provocada por ações estatais para dinamizar o mercado interno a partir da indústria. A defesa do desenvolvimento pautado na industrialização era fundamentada por alguns exemplos favoráveis, como os Estados Unidos e a Inglaterra (FONSECA, 2003).

Na década de 1950, a tese predominante passou a ser a cepalina, que identificava a deterioração dos termos de troca como nociva para países com pauta exportadora dependente de commodities agrícolas, o que geraria déficits nas transações internacionais. Em resposta a tal situação, a escola cepalina recomendava para os países latino-americanos a implementação de políticas de industrialização por substituição de importações (PREBISCH, 1962).

Políticas desse tipo foram adotadas no Brasil de 1950 até a década de 1980, influenciadas e direcionadas por um Estado desenvolvimentista com as funções de induzir e sinalizar investimentos e, até mesmo, investir e produzir diretamente visando à industrialização. O auge dessas políticas ocorreu de 1968 a 1979, durante o regime militar, no período que compreende o Milagre Econômico e o II Plano Nacional de Desenvolvimento (PND), gerando significativas expansões da industrialização e do produto agregado (TAVARES, 1975; BAER, 1993; CARNEIRO, 1990; LAGO, 1990; SILVA, 2003).

Na década de 1980, o modelo de substituição de importações esgotou-se e os principais debates sobre o tema passaram a ser a possivel desindustrialização, considerando suas causas e consequências e a desconcentração espacial da indústria. No primeiro, havia duas posições: uma defendia a hipótese de desindustrialização induzida por doença holandesa, que teria sido intensificada pelas políticas de abertura comercial e financeira; a outra defendia a desindustrialização como um fenômeno natural devido à expansão da participação do setor de serviços. As- 
sim, diferenças da produtividade do trabalho e da elasticidade-renda explicariam a desindustrialização (NAKAHODO; JANK, 2006; OREIRO; FEIJÓ, 2010).

Em relação ao segundo debate, Cano (1981) aponta que a industrialização brasileira foi espacialmente desigual até os anos 1970, concentrando-se na região Sudeste, especialmente em São Paulo. A tendência de concentração foi, em parte, revertida pelo Milagre Econômico e II Plano Nacional de Desenvolvimento (PND), devido a ações federais. A posteriori, a desconcentração parcial decorreu de guerra fiscal nas esferas subnacionais e de decisões das empresas em busca de vantagens comparativas, como custos e mercados (CANO, 1997; SABOIA, 2001).

Voltando a atenção para a distribuição de renda no Brasil, pode-se dizer que, em certo grau e em alguns momentos, foi atrelada à dinâmica da indústria. Por exemplo, a concentração espacial da indústria também resultou em distribuição desigual da renda no território brasileiro (CANO, 1981). O já mencionado livro de Furtado (1967) é pioneiro no assunto ao advogar que a predominância do setor agrário na fase inicial de desenvolvimento brasileiro era regida sob o sistema de concentração de propriedades e outras atividades nas mãos de poucos. Porém, tal debate só ganhou maior destaque a partir do Milagre Econômico, dado que o crescimento induzido pela industrialização foi acompanhado por pior distribuição de renda (LANGONI, 1973).

Nesse contexto, emergiu o debate conhecido como controvérsia de 70, no qual algumas visões tentaram explicar a piora da desigualdade de renda. Segundo Gandra (2005), o debate foi composto por três vertentes de interpretações. A primeira baseava-se na Teoria do Capital Humano. Nessa linha, Langoni (1973) defende a elevação da desigualdade como decorrência de um déficit de mão de obra qualificada. O baixo número de profissionais qualificados teria superestimado seus salários, elevando a diferença em relação aos dos menos qualificados. Um agravante dessa situação seria a estrutura produtiva da economia brasileira, com setor rural atrasado comparativamente ao industrial, o que resultava em diferenças salariais entre esses setores. Tal abordagem está alinhada à de economia dual, que é discutida na próxima subseção.

A segunda vertente é representada pelos trabalhos de Fishlow $(1972,1978)$ e Hoffmann e Duarte (1972), para os quais, as principais causas do aumento da concentração de renda foram as políticas do governo militar, que provocaram compressão salarial. É o caso do Plano de Ação Econômica do Governo (Paeg), que alterou a forma de reajuste do salário mínimo. Este passou a tomar como referência a inflação projetada pelo governo, que, quase sempre, era inferior à efetiva. Como o sistema político não permitia greves ou pressões para negociar a alteração da forma de reajuste, houve queda do poder de compra do salário mínimo. Assim, o decorrente processo inflacionário, junto com o crescimento econômico e o arro- 
cho salarial redistribuíram a renda em favor de alguns setores urbanos - principalmente trabalhadores administrativos e do setor financeiro - e empresários.

Já a terceira vertente teve como referência os trabalhos de Bacha (1978) e Bacha e Taylor (1980), que utilizam argumentos da sociologia e da organização da estrutura hierárquica das empresas. Para formalizarem a interpretação, dividiram os trabalhadores em duas categorias: white-collars e blue-collars. A primeira era composta por trabalhadores de alta qualificação com remunerações atreladas aos resultados da empresa; a segunda, por trabalhadores em geral, com salários definidos pela demanda e oferta no mercado de trabalho. A diferença nas formas de determinação dos salários criava um leque salarial que elevava a desigualdade de renda.

Em paralelo ao debate da controvérsia de 70, outros trabalhos tentaram explicar porque a industrialização contribuiu para a piora da distribuição de renda. Destacam-se Tavares (1975) e Mello (1986), que entendiam que a concentração de renda já estava presente na produção brasileira, mas a industrialização a aprofundou e escancarou. Esses autores, em parceria com outros da escola de Campinas, defendiam que a concentração piorou devido à forma como se deu a industrialização, que priorizou alguns setores com características concentradoras, como o de bens duráveis. Logo, entendia-se que o crescimento induzido pela industrialização não iria reduzir automaticamente o nível de desigualdade de renda (CARDOSO; POCHMANN, 2000).

Nas décadas seguintes, o debate sobre a industrialização como causa da concentração de renda foi deixado um pouco de lado e outras discussões ganharam evidência. Nos anos 1990, destacam-se as visões estrutural integrada, focada no papel da inflação, e unilateralista, que retoma, em parte, aspectos de Langoni (1973) - fundamentação na Teoria do Capital Humano e na heterogeneidade educacional (BONELLI; RAMOS, 1993; BARROS; HENRIQUES; MENDONCA, 2000; ROCHA; SANTOS; ROSADO, 2013). Nos anos 2000, a atenção voltou-se para a redução observada na desigualdade. As interpretações enfatizaram efeitos de políticas distributivas, de valorização do salário mínimo e educacionais (HOFFMANN; NEY, 2008; DEDECCA, 2015; BARROS; FOGUEL; ULYSSEA, 2007).

\subsection{Hipóteses da Relação Desigualdade-Crescimento: a Abordagem da Economia Dual}

Além dos debates internos realizados pela academia brasileira, discutidos anteriormente, existe um debate em âmbito internacional que tenta entender a dinâmica entre industrialização, crescimento econômico e distribuição de renda. Uma das teorias mais discutidas é a da CK, que, inclusive, embasa uma das teses de Langoni (1973) para explicar a concentração de renda a partir do Milagre Econômico - atraso do setor rural em relação ao industrial. 
Kuznets (1955), com dados referentes aos séculos XIX e XX da Inglaterra, Alemanha e Estados Unidos, mostrou evidências que sugerem a elevação da desigualdade de renda com o crescimento econômico em níveis menores de renda per capita e que, a partir de certo nível, a desigualdade cai. Ou seja, existiria uma relação próxima a um $U$ invertido entre desigualdade e nível de renda. Tal potencial relação ficou conhecida como teoria (ou hipótese) da CK.

Diversos trabalhos testaram a CK, parte deles levantando algumas possíveis justificativas. Na survey de Deutsch e Silber (2000), as possíveis justificativas são divididas em três grupos, segundo a visão adotada: a) economia dual; b) crescimento endógeno (ou new-growth); e c) teoria da escolha pública. O último e, principalmente, o primeiro são os que aqui merecem destaque por associarem a dinâmica da industrialização como um dos condicionantes da CK. ${ }^{3}$

Para a abordagem dual, que foi, inclusive, usada como explicação no trabalho de Kuznets (1955), a migração de trabalhadores entre setores da economia, do menos para o mais dinâmico (ou do tradicional para o moderno), causaria, inicialmente, o aumento da desigualdade de renda, mas a consolidação do novo setor levaria à queda da desigualdade. Tal dinâmica ocorreria na transição de uma economia com predominância da agropecuária para uma industrial. Assim, seria atrelada à industrialização. No início do processo, a produtividade marginal do trabalho e, consequentemente, os rendimentos na indústria aumentam mais rapidamente, aumentando a desigualdade de renda. Porém, à medida que a industrialização se consolida, com migração de grande parte dos trabalhadores, motivados pelo diferencial de salário, a desigualdade cairia.

Lewis (1954) e Ramos (1991), baseados em modelos de surplus labor, apresentam uma interpretação alternativa pela abordagem dual. A concentração de renda inicial em função do crescimento econômico se dá a uma taxa maior de lucros no setor moderno, que, em relação ao tradicional, está em processo de expansão. Ao longo do tempo, com a economia atingindo o ponto no qual o trabalho passa a ser remunerado segundo a produtividade marginal no setor tradicional, o sistema assume características neoclássicas e a desigualdade tende a reduzir.

Os trabalhos relacionados à teoria da escolha pública fundamentam seus argumentos na interação entre mecanismo político e estrutura econômica. Segundo Glaeser (2005), o efeito da industrialização sobre a distribuição de renda seria por meio de políticas redistributivas, que tendem a ser mais adotadas à medida que aumenta a urbanização - associada à expansão da participação da indústria na economia -, o que resulta em maior proximidade entre as pessoas e, assim, maiores capacidades

3 O principal argumento dos trabalhos do segundo grupo é que, com baixos níveis de renda per capita, imperfeições nos mercados de crédito e distribuições desiguais do capital humano e, consequentemente, da renda são condições para a economia desenvolver-se. Ao longo do desenvolvimento, há transbordamento de conhecimento para os mais pobres, caindo a desigualdade (AGHION; BOLTON, 1992; GALOR; TSIDDON, 1996). 
de organização e pressão sobre governantes para o atendimento de suas demandas (controle social). A maior organização também pode gerar maior poder de barganha aos trabalhadores nas negociações salariais, afetando a desigualdade de renda.

Estudos mais recentes, embasados em evidências empíricas, defendem que a relação entre desigualdade de renda e crescimento econômico assumiria, na verdade, um formato próximo a um $N$, e não o $U$ invertido da $\mathrm{CK}$, pois a desigualdade de renda voltaria a aumentar devido ao crescimento em níveis maiores de renda per capita. Os trabalhos que defendem a relação desigualdade-crescimento no formato $N$ também o justificam pela abordagem da economia dual, destacando o papel da dinâmica da (des)industrialização. Segundo Bishop, Formby e Thistle (1991) e List e Gallet (1999), a volta do aumento da desigualdade de renda em níveis mais elevados de renda per capita decorreria da transição de uma economia com predominância industrial para uma economia baseada no setor de serviços - ocorrência de uma desindustrialização natural. Assim como na migração de trabalhadores da agropecuária para a indústria, a migração desta para os serviços elevaria a desigualdade de renda devido aos diferenciais de produtividade e de rendimentos dos setores.

$\mathrm{Na}$ literatura, existem outras possíveis explicações para o formato $N$. Katz e Murphy (1992), por exemplo, defendem que o aumento da desigualdade de renda com o crescimento em níveis maiores de renda decorre do aumento da demanda por trabalhadores mais qualificados devido a mudanças tecnológicas e expansões do comércio internacional, entre outros aspectos que alteram a dinâmica do mercado de trabalho. Já Glaeser (2005) e Piketty (2006) justificam o formato N por meio de questões tributárias, legislações trabalhistas e políticas redistributivas.

\section{Estratégias Empíricas e Dados}

Para se avaliar como a industrialização afeta a distribuição dos rendimentos do trabalho nos municípios brasileiros, são feitas estimações em painel com dados municipais de 2000 e 2010 - últimos anos censitários. Os métodos empregados são: a) efeitos fixos - mínimos quadrados ordinários (MQO) com erros padrões robustos e estimador within (variáveis em desvios em relação às suas médias para cada observação); e b) efeitos aleatórios - mínimos quadrados generalizados (MQG). O teste de Hausman é feito para verificar qual dos métodos é o adequado (BALTAGI, 2001; GREENE, 2011). Os modelos estimados baseiam-se na equação 1:

$$
\begin{aligned}
& D_{i t}=\alpha_{0}+\alpha_{1} V I_{i t}+\alpha_{2} V I_{i t}^{2}+\alpha_{3} E I_{i t}+\alpha_{4} E I_{i t}^{2}+\alpha_{5} Y_{i t}+\alpha_{6} Y_{i t}^{2}+\alpha_{7} Y_{i t}^{3}+\alpha_{8} X_{i t} \\
& +T_{t}+u_{i}+\varepsilon_{i t}
\end{aligned}
$$

na qual $D_{i t}$ é a variável dependente do município $i$ no ano $t ; \alpha_{0}$ é a constante; $V I_{i t}, E I_{i t}$ e $Y_{i t}$ são as variáveis explicativas de interesse; $\alpha_{1}$ a $\alpha_{7}$ são os coeficientes das 
variáveis de interesse; $X_{i t}$ é o vetor de variáveis de controle; $\alpha_{8}$ é o vetor de coeficientes dos controles; $T_{t}$ é uma dummy para o ano de 2010 (2000 como default); $u_{i}$ é os efeitos fixos; e $\varepsilon_{\text {it }}$ é o erro.

A variável dependente $D_{i}$ é o índice de Theil- $L$ dos rendimentos do trabalho para maiores de 18 anos (Theil- $L$ trabalho). Este mede a desigualdade na distribuição de indivíduos ocupados de 18 anos de idade ou mais, pelo rendimento de todos os trabalhos, calculada pelo logaritmo da razão entre as médias aritmética e geométrica dos rendimentos individuais. É igual a zero quando não há desigualdade de renda e é tendente ao infinito quando a desigualdade tende ao máximo. Os índices para cada município brasileiro são calculados e disponibilizados pelo PNUD (NSTITUTO DE PESQUISA ECONÔMICA APLICADA, 2013), a partir de dados dos Censos Demográficos de 2000 e 2010 do IBGE (INSTITUTO BRASILEIRO DE GEOGRAFIA E ESTATÍSTICA, 2000, 2010). A escolha desse índice decorre do estudo averiguar o efeito da participação relativa de um setor produtivo sobre a desigualdade de renda. Assim, como já mencionado, este estudo insere-se no debate sobre distribuição pessoal e setorial da renda, que a trata como função de atributos pessoais e setoriais que afetam a produtividade do trabalho - prêmios por atributos ${ }^{4}$ (ALVAREZ, 1995).

Pelo conceito original, discutido por Rowthorn e Wells (1987) e Rowthorn e Ramaswamy (1997), desindustrialização é um processo de retração significativa e persistente da participação da indústria no emprego total da economia. Tregenna (2009) propõe um conceito ampliado para o processo: quedas concomitantes das participações industriais no emprego e produto. Segundo a autora, a definição de desindustrialização em termos apenas de emprego é limitada em função de vários fatores, destacando-se o fato de que um aumento da produtividade da indústria maior do que o observado nos serviços pode induzir à desindustrialização somente pelo emprego.

Assim, optou-se por considerar tanto a participação do valor adicionado da indústria (VA indústria) no PIB do município $i$ no ano $t$ - razão entre o VA industrial e o PIB, representada na equação 1 por $V I_{i t}-$, quanto a participação da indústria no emprego ("emprego indústria") - representada em na equação 1 por $E I_{i t}$. Por se tratarem de participações relativas, suas interpretações são aumentos ou reduções do produto ou emprego industrial comparativamente ao agregado de outros setores econômicos - serviços, agropecuária e público (administração, saúde e educação públicas e seguridade social). As informações dos VAs setoriais e dos PIBs são oriundas do IBGE. Já a variável "emprego indústria" é calculada e disponibilizada pelo PNUD (INSTITUTO DE PESQUISA ECONÔMICA APLICADA, 2013), a partir de dados do IBGE, representando a razão entre as pessoas de 18 anos de idade ou mais ocupadas no setor industrial e o total de pessoas ocupadas da mesma faixa etária.

Esse tipo de modelagem foi proposta por Mincer (1974) e ficou conhecida como equação de salários minceriana. 
As participações da indústria no produto e no emprego são consideradas na equação 1 em funções quadráticas (polinômios de segundo grau) - $V I_{i t}$, e $V I_{i t}^{2}$ e $E I_{i t}$ e $E I_{i t}^{2}$, respectivamente. Essa é a proposta deste estudo para testar a hipótese da abordagem da economia dual de que: a) em estágios iniciais da industrialização, a migração de trabalhadores da agropecuária para a indústria e o diferencial de aumento da produtividade do trabalho, maior na indústria, pioram a desigualdade de rendimentos do trabalho; b) em estágios mais avançados, a migração se estabiliza, a indústria se consolida e, assim, a desigualdade passa a diminuir em função do aumento da participação do setor industrial (KUZNETS, 1955; DEUTSCH; SILBER, 2000). Como já mencionado, tal hipótese é uma das justificativas da literatura para a hipótese da CK. Porém, aqui é proposta uma forma de testar especificamente o formato da relação desigualdade-industrialização.

Vale ressalvar que maiores participações da indústria no produto e emprego em relação aos serviços também implicam, pela abordagem da economia dual, menor desigualdade de renda. Como discutido anteriormente, a expansão dos serviços em relação à indústria é uma das explicações da possível volta do aumento da desigualdade em níveis maiores de renda, o que justificaria a relação desigualdade-crescimento em N (BISHOP; FORMBY; THISTLE, 1991; LIST; GALLET, 1999). Outro aspecto a considerar é que evidências para o Brasil sinalizam diferenciais de rendimentos entre os setores público e privados, em favor do primeiro (MARCONI, 1997; BELLUZZO; ANUATTI NETO; PAZELLO, 2005). Assim, é plausível esperar que, quanto maiores as participações industriais no produto e emprego em relação ao setor público, menor a desigualdade de renda.

Para corroborar a hipótese da economia dual, as evidências devem sugerir uma relação não linear entre a desigualdade de rendimentos e a industrialização, em formato próximo a um $U$ invertido. Ou seja, a desigualdade aumenta com a industrialização em níveis pequenos de participação industrial e diminui em níveis mais elevados. Para isso, os coeficientes estimados das variáveis em nível devem ser significativos e positivos; já os coeficientes das variáveis ao quadrado devem ser significativos e negativos. Assim, para as participações no produto e no emprego, respectivamente $\alpha_{1}>0$ e $\alpha_{1}<0$ e $\alpha_{3}>0$ e $\alpha_{4}<0$, logo a hipótese é corroborada se as relações tiverem turning points (pontos de máximo). Derivando-se a equação 1 em relação às variáveis, a participação industrial média no produto no turning point $(\overline{V I})$ é calculada pela equação 2 . Já a participação média no emprego no turning point $(\overline{E I})$ é calculada pela equação 3:

$$
\begin{aligned}
& \overline{V I}=-\alpha_{1} / 2 \alpha_{2} \\
& \overline{E I}=-\alpha_{3} / 2 \alpha_{4}
\end{aligned}
$$


Deve-se apontar que a relação entre industrialização e desigualdade de rendimentos pode advir de efeitos composição e concentração. Segundo Soares (2006), alterações na desigualdade de um local em dado período, medido por índices de concentração - como o Theil-L -, são sensíveis a tais efeitos. Para o escopo do presente estudo, o efeito composição é a variação da desigualdade provocada por alterações das participações dos setores produtivos. Já o efeito concentração é a variação da desigualdade por mudanças na concentração da renda nos setores. Por exemplo, se um setor com concentração de renda bastante distinta dos demais tem sua participação no emprego (ou produto) alterada, ocorre variação da desigualdade pelo efeito composição. Já se um setor com grande participação apresenta variação de sua concentração de renda, ocorre alteração da desigualdade por efeito concentração (HOFFMANN; NEY, 2008).

Considerando-se evidências de outros trabalhos de que as atividades industriais tendem a concentrar menos os rendimentos do trabalho no Brasil do que os demais setores (MARCONI, 1997; BELLUZZO; ANUATTI NETO; PAZELLO, 2005; HOFFMANN, 2011; OLIVEIRA; SILVEIRA NETO, 2016), seria plausível esperar que o aumento da participação industrial sempre resultaria em redução da desigualdade de renda nos municípios, pelo efeito composição. Contudo, se for constatada a relação não linear proposta, pode-se afirmar que a industrialização impacta a desigualdade de rendimentos do trabalho por combinações dinâmicas dos efeitos composição e concentração, o que estaria de acordo com as hipóteses da economia dual, apresentadas na seção anterior.

A Tabela 1 mostra algumas estatísticas descritivas para as variáveis dependente $\left(D_{i t}\right)$ e explicativas de interesse $\left(V I_{i t}\right.$ e $\left.E I_{i t}\right)$ para os anos de 2000 e 2010. Observa-se que o índice de Theil- $L$ dos rendimentos do trabalho municipal médio reduziu de 2000 a 2010, assim como seu desvio padrão, sinalizando melhora da desigualdade no período. Já as participações industriais no produto (VA indústria) e emprego (emprego indústria), na média, aumentaram pouco.

Tabela 1 - Variáveis dependente e explicativas de interesse: estatísticas descritivas (2000 e 2010)

\begin{tabular}{l|c|c|c|c|c|c|c|c}
\hline \multirow{2}{*}{ Covariadas } & \multicolumn{4}{|c|}{2000} & \multicolumn{4}{|c}{2010} \\
\cline { 2 - 9 } & Média & $\begin{array}{c}\text { Desvio } \\
\text { padrão }\end{array}$ & Mínimo & Máximo & Média & $\begin{array}{c}\text { Desvio } \\
\text { padrão }\end{array}$ & Mínimo & Máximo \\
\hline $\begin{array}{l}\text { Theil- } L \\
\text { trabalho }\end{array}$ & 0,477 & 0,154 & 0,000 & 1,420 & 0,389 & 0,122 & 0,000 & 1,400 \\
\hline VA indústria & 0,145 & 0,122 & 0,012 & 0,917 & 0,160 & 0,125 & 0,009 & 0,931 \\
\hline $\begin{array}{l}\text { Emprego } \\
\text { indústria }\end{array}$ & 0,158 & 0,099 & 0,003 & 0,739 & 0,167 & 0,096 & 0,009 & 0,701 \\
\hline
\end{tabular}

Fonte: Elaboração própria a partir de PNUD (INSTITUTO DE PESQUISA ECONÔMICA APLICADA, 2013) e IBGE $(2010,2000)$. 
Como já mencionado, a hipótese da CK pressupõe uma relação entre a desigualdade de renda e o nível de renda per capita no formato de um $U$ invertido, ou seja, em níveis baixos de renda per capita, a desigualdade aumenta com o crescimento econômico; porém, atingido certo nível, a desigualdade passa a cair (KUZNETS, 1955; DEUTSCH; SILBER, 2000). No entanto, evidências de alguns trabalhos contestam a CK, sinalizando que a queda da desigualdade com o crescimento econômico pode não se manter em níveis maiores de renda. Assim, a relação desigualdade-crescimento teria, na verdade, um formato próximo a um $N$ (BISHOP; FORMBY; THISTLE, 1991; LIST; GALLET, 1999).

O presente estudo também contribui para a literatura empírica com evidências sobre a relação desigualdade-crescimento por meio de testes das hipóteses da CK e do N. Para isso, é inserido, como variável explicativa, o PIB per capita dos municípios ( $\mathrm{R} \$$ milhões de 2000) em uma função cúbica (polinômio de terceiro grau), como é ilustrado na equação 1, pelos termos $Y_{i t}, Y_{i t}^{2}$ e $Y_{i t}^{3}$. A hipótese do $N$ é corroborada se os coeficientes associados ao PIB per capita forem significativos, positivos em nível e ao cubo $\left(\alpha_{5}>0\right.$ e $\left.\alpha_{7}>0\right)$ e negativos ao quadrado $\left(\alpha_{6}<0\right)$. Para confirmar o formato, deve ser realizado o teste da segunda derivada: a) obter a primeira derivada da equação 1 em relação a, considerando os coeficientes estimados $\left(\alpha_{5}, \alpha_{6}\right.$ e $\left.\alpha_{7}\right)$; b) calcular os pontos críticos médios; c) obter a segunda derivada e substituir os pontos críticos. Se um dos valores for negativo e o outro positivo, há pontos de máximo e mínimo (CHIANG, 1982), corroborando o formato próximo a um N. Já se $\alpha_{5}>0\left(Y_{\mathrm{it}}\right)$, $\alpha_{6}<0\left(Y_{i t}^{2}\right)$ e $\alpha_{7}<0\left(Y_{i t}^{3}\right)$ ou $\alpha_{7}$ não for significativo, a relação desigualdade-crescimento assume o formato da $\mathrm{CK}$. Quaisquer outras combinações de sinais refutam os dois formatos. Os dados para o cálculo dos PIBs per capita são oriundos do IBGE (2010; 2000). A Tabela 2 apresenta algumas estatísticas descritivas.

Tabela 2 - Covariadas: descrições e estatísticas descritivas (2000 e 2010)

\begin{tabular}{|c|c|c|c|c|c|}
\hline \multirow[b]{2}{*}{ Covariadas } & \multirow[b]{2}{*}{ Descrições } & \multicolumn{2}{|c|}{2000} & \multicolumn{2}{|c|}{2010} \\
\hline & & Média & $\begin{array}{l}\text { Desvio } \\
\text { padrão }\end{array}$ & Média & $\begin{array}{l}\text { Desvio } \\
\text { padrão }\end{array}$ \\
\hline PIB per capita & PIB per capita ( $\mathrm{R} \$$ milhões de 2000$)$ & 0,004 & 0,005 & 0,006 & 0,007 \\
\hline Instrução & $\begin{array}{l}\text { Porcentagem de ocupados com ensino médio: } \\
18 \text { anos ou mais }\end{array}$ & 0,169 & 0,087 & 0,304 & 0,098 \\
\hline População & População: milhares habitantes & 30,76 & 186,62 & 33,83 & 200,28 \\
\hline Urbanização & Porcentagem de população urbana & 0,589 & 0,233 & 0,638 & 0,220 \\
\hline Mulheres & Porcentagem de mulheres na população & 0,492 & 0,014 & 0,495 & 0,016 \\
\hline Não brancos & Porcentagem de não brancos na população & 0,475 & 0,255 & 0,533 & 0,242 \\
\hline Jovens & $\begin{array}{l}\text { Porcentagem da população de } 18 \text { anos ou } \\
\text { mais }\end{array}$ & 0,618 & 0,060 & 0,685 & 0,056 \\
\hline Formalização & $\begin{array}{l}\text { Porcentagem de ocupados formais: } 18 \text { anos } \\
\text { ou mais }\end{array}$ & 0,361 & 0,181 & 0,435 & 0,193 \\
\hline
\end{tabular}

Fonte: Elaboração própria a partir de PNUD (INSTITUTO DE PESQUISA ECONÔMICA APLICADA, 2013) e IBGE $(2010,2000)$ 
O controle pelo PIB per capita pode suavizar um potencial viés de omissão de variáveis explicativas importantes, pois é correlacionado a várias dimensões do desenvolvimento econômico que afetam a desigualdade de renda. Ademais, ao ser controlado em uma função, é possível captar os efeitos dos outros fatores, discutidos na seção anterior, que explicariam a relação entre desigualdade de renda e crescimento econômico, tanto no formato da CK quanto em $N$, de modo que as prováveis relações encontradas entre a desigualdade de rendimentos do trabalho e as participações industriais no produto e no emprego possam ser interpretadas, com maior robustez, como efeitos causais da industrialização sobre a desigualdade de renda.

Vale ressalvar que as hipóteses da CK, do formato $\mathrm{N}$ e da economia dual, conforme já discutido, baseiam-se em processos históricos de transformação da economia, enquanto este estudo propõe exercícios empíricos com dados referentes aos anos de 2000 e 2010, ou seja, para um período de uma década, tempo que pode ser relativamente curto para que os processos de transformação que fundamentam as hipóteses se concretizem. Em contrapartida, conta a favor o fato de os municípios serem as unidades de análise e serem bastante heterogêneos - o que, em algum grau, é sinalizado pelos dados das Tabelas 1 e 2. Assim, ao se considerar dados de municípios em estágios distintos de industrialização e desenvolvimento econômico (e com processos históricos próprios de transformação econômica), é plausível inferir que os prováveis resultados aqui obtidos possam decorrer dos aspectos preconizados pelas hipóteses testadas.

Uma recomendação da literatura sobre a $\mathrm{CK}$, adotada neste estudo, é o controle por outras características observadas dos locais - municípios - que também podem afetar a distribuição da renda e que são variantes no tempo (AHLUWALIA, 1976; ANAND; KANBUR, 1993; JHA, 1996). A Tabela 2 apresenta o vetor de variáveis de controle (covariadas) $X_{\mathrm{it}}$ considerado nas estimações, suas descrições e estatísticas descritivas para 2000 e 2010.

Em relação às variáveis "instrução" e "jovens", deve-se apontar que a literatura fundamentada na Teoria do Capital Humano e na equação minceriana de salários defende que o aumento da média de pessoas com maiores níveis de educação e idade (proxy para experiência) melhoram a distribuição da renda. Porém, existiriam pontos de inflexões que geram saltos no rendimento, como, por exemplo, a conclusão de ciclos de educação e o alcance da maior idade (MINCER, 1974; ALVAREZ, 1995). Assim, optou-se pelo ensino médio como referência por ser um dos mais importantes pontos de inflexão quando se trata de educação e pela faixa etária acima de 18 anos por ser a idade em que as pessoas normalmente entram no mercado de trabalho formal.

No Brasil, a literatura sinaliza que trabalhadores de áreas urbanas tendem a ser melhor remunerados e que há diferenciais de salários entre mulheres e homens e entre não brancos e brancos, o que decorre de discriminações por gênero 
e etnia/cor (BARROS; FOGUEL; ULYSSEA, 2007). Assim, é importante controlar as variáveis "urbanização", "mulheres" e "não brancos" para captarem os efeitos das distribuições dos trabalhadores (espacial, por gênero e etnia/cor) na desigualdade.

Em relação à variável "formalização", que representa os trabalhadores que possuem carteira de trabalho assinada, Maia (2013) mostra que eles possuem, no Brasil, remuneração média maior do que os trabalhadores ocupados em posições informais. Ademais, outra constatação é que a formalização melhora a distribuição de renda. A variável "população", em conjunto com as demais, controla o tamanho do mercado de trabalho em cada um dos municípios brasileiros.

Além das covariadas, também são controladas as características não observadas distintas entre os municípios e constantes no tempo - efeitos fixos $\left(\mu_{i}\right)$ - e as características constantes entre os municípios e variantes no tempo - efeito fixo temporal $\left(T_{t}\right)$, controlado pela dummy para o ano de 2010. De acordo com a literatura, atributos históricos, institucionais e culturais específicos de cada local influenciam a desigualdade de renda (DEUTSCH; SILBER, 2000).

Para averiguar a robustez dos resultados frente a possíveis correlações entre as variáveis explicativas de interesse (multicolinearidade), são estimados modelos para as três especificações. A especificação I representa o modelo completo, como expresso na equação 1. Na especificação II, é retirado o polinômio de segundo grau referente à participação industrial no emprego, mantendo a função quadrática da participação industrial no produto, a função cúbica do PIB per capita, as covariadas e a dummy 2010. Na especificação III, são controlados a função quadrática da participação da indústria no emprego, a função cúbica do PIB per capita, as demais covariadas e a dummy 2010, ou seja, não é considerada na estimação a participação industrial no produto.

Com o intuito de avaliar se as possíveis relações entre a desigualdade dos rendimentos do trabalho e as participações industriais no produto e no emprego não são lineares, mas com um formato distinto do proposto, é estimado um modelo baseado na equação 2 - especificação IV -, no qual as participações industriais são consideradas em funções cúbicas - $V I_{i t}, V I_{i t}^{2}$ e $V I_{i t}^{3}$ e $E I_{i t}, E I_{i t}^{2}$ e $E I_{i t}^{3}$. A combinação dos coeficientes em nível, ao quadrado e ao cubo e, se for o caso, testes da segunda derivada apontarão os formatos obtidos para as relações. Se os coeficientes das participações em nível e ao quadrado respeitarem o padrão para inferir o $U$ invertido e os coeficientes ao cubo $\left(\alpha_{9}\right.$ e $\left.\alpha_{10}\right)$ forem negativos ou não significativos, tal formato é confirmado:

$$
\begin{aligned}
& D_{i t}=\alpha_{0}+\alpha_{1} V I_{i t}+\alpha_{2} V I_{i t}^{2}+\alpha_{9} V I_{i t}^{3}+\alpha_{3} E I_{i t}+\alpha_{4} E I_{i t}^{2}+\alpha_{10} E I_{i t}^{3}+\alpha_{5} Y_{i t}+\alpha_{6} Y_{i t}^{2} \\
& +\alpha_{7} Y_{i t}^{3}+\alpha_{8} X_{i t}+T_{t}+u_{i}+\varepsilon_{i t}
\end{aligned}
$$

Uma crítica que as estimações até aqui propostas podem sofrer refere-se ao índice Theil- $L$ do trabalho variar de zero ao infinito. Assim, sofre censura no limite inferior. Na presença de censura na variável dependente, as estimações por MQO, 
como no painel com efeitos fixos, podem ser viesadas e inconsistentes. Uma opção é o método tobit em painel, com estimação por máxima verossimilhança. Tal método é vantajoso por usar uma distribuição mais adequada para dados censurados. Porém, não controla os efeitos fixos, e os coeficientes não são efeitos médios ou marginais, mas os sinais podem ser interpretados (BALTAGI, 2001; GREENE, 2011).

Assim, para averiguar a robustez dos resultados frente à censura, são estimados modelos baseados nas equações 1 e 4 - especificações I e IV -, desconsiderando os efeitos fixos $\left(\mu_{i}\right)$, por tobit em painel. Devido às especificidades do método, não são mensurados os turning points, mas é possível inferir os formatos das relações entre desigualdade de renda, participações industriais e PIB pelos sinais e significâncias dos coeficientes, de acordo com os padrões já apontados.

Os métodos já propostos são para estimações paramétricas. Para evidências adicionais, é interessante usar regressões não paramétricas para ajustar curvas que representam as relações entre a desigualdade dos rendimentos e as participações industriais. O método escolhido é o de kernel-weighted local polynomial regression, que permite a visualização gráfica das relações entre variáveis sem a imposição prévia de uma forma funcional, com os dados falando por si mesmos. ${ }^{5}$ Para ajustar melhor as relações, as participações industriais (VA indústria e emprego indústria) são consideradas em logaritmo natural (ln), e é considerado apenas o ano de 2010.

\section{Análises dos Resultados}

A seguir, são analisados os resultados que possibilitam averiguar como a industrialização afeta a distribuição dos rendimentos do trabalho nos municípios brasileiros. Para não fugir do escopo do estudo, os coeficientes das covariadas e da dummy 2010 não são reportados, assim os coeficientes são estimados por efeitos aleatórios, pois os testes de Hausman sinalizam, em todas as estimações, a melhor adequação dos efeitos fixos (estatísticas dos testes são significativas). ${ }^{6}$

A Tabela 3 mostra os resultados das estimações paramétricas. Os coeficientes estimados associados à função quadrática da participação da indústria no produto (VA indústria), em todas as estimações em que é considerada, são significativos, sendo positivos em nível e negativos ao quadrado. Já os coeficientes para a variável ao cubo não são significativos (especificação IV). Tais resultados são constatados tanto por efeitos fixos como por tobit em painel, sugerindo que a relação desigualdade-industrialização, pelo lado do produto, tem um formato próximo a um $U$ invertido. Ou seja, que a desigualdade dos rendimentos do trabalho aumenta em função da industrialização até certa participação industrial no produto

\footnotetext{
5 Para mais detalhes, ver, por exemplo, Cleveland e Devlin (1988), Jones, Davies e Park (1994) e Loader (1999).

6 Os resultados não reportados podem ser solicitados aos autores.
} 
(turning point), a partir da qual passa a cair. Na especificação I, o turning point $(\overline{V I})$ é, em uma participação média da indústria no produto, de 23,1\%; na especificação II, o turning point é de 22,5\%; e, na especificação IV, o turning point é de 18,6\%.

Tabela 3 - Resultados: estimações por painel com efeitos fixos e tobit em painel

\begin{tabular}{|c|c|c|c|c|c|c|}
\hline \multirow{3}{*}{$\begin{array}{l}\text { Variáveis / } \\
\text { estatísticas }\end{array}$} & \multicolumn{6}{|c|}{ Métodos / especificações } \\
\hline & \multicolumn{3}{|c|}{ Efeitos fixos } & \multicolumn{3}{|c|}{ Tobit } \\
\hline & I & II & III & IV & I & IV \\
\hline \multirow{2}{*}{$\begin{array}{l}\text { VA indústria } \\
(0,074)\end{array}$} & $0,281^{(\mathrm{a})}$ & $0,274^{(\mathrm{a})}$ & & $0,443^{(a)}$ & $0,054^{(\mathrm{c})}$ & $0,308^{(a)}$ \\
\hline & $(0,074)$ & & $(0,142)$ & $(0,022)$ & $(0,078)$ & \\
\hline \multirow{2}{*}{$\begin{array}{l}\text { VA indústria } 2 \\
(0,116)\end{array}$} & $-0,608^{(a)}$ & $-0,608^{(a)}$ & & $-1,191^{(a)}$ & $-0,246^{(a)}$ & $-1,101^{(a)}$ \\
\hline & $(0,115)$ & & $(0,441)$ & $(0,057)$ & $(0,250)$ & \\
\hline \multirow{2}{*}{ VA indústria ${ }^{3}$} & & & & 0,518 & & 0,744 \\
\hline & & & $(0,393)$ & & $(0,719)$ & \\
\hline \multirow{2}{*}{$\begin{array}{l}\text { Emprego } \\
\text { indústria } \\
(0,095)\end{array}$} & $0,249^{(a)}$ & & $0,263^{(a)}$ & $0,622^{(a)}$ & $0,173^{(a)}$ & $0,836^{(a)}$ \\
\hline & & $(0,095)$ & $(0,182)$ & $(0,049)$ & $(0,098)$ & \\
\hline \multirow{2}{*}{$\begin{array}{l}\text { Emprego } \\
\text { indústria }{ }^{2} \\
(0,188)\end{array}$} & $-0,680^{(a)}$ & & $-0,708^{(a)}$ & $-2,463^{(a)}$ & $-0,649^{(a)}$ & $-3,698^{(a)}$ \\
\hline & & $(0,188)$ & $(0,717)$ & $(0,091)$ & $(0,391)$ & \\
\hline \multirow{2}{*}{$\begin{array}{l}\text { Emprego } \\
\text { indústria }^{3}\end{array}$} & & & & 2,293 & & 3,735 \\
\hline & & & $(2,814)$ & & $(3,454)$ & \\
\hline \multirow{2}{*}{$\begin{array}{l}\text { PIB per capita } \\
(2,327)\end{array}$} & $27,164^{(a)}$ & $26,840^{(a)}$ & $23,389^{\text {(a) }}$ & $26,942^{(a)}$ & $19,421^{(a)}$ & $20,559^{(a)}$ \\
\hline & $(2,319)$ & $(2,362)$ & $-2,353$ & $(1,147)$ & $(1,1780$ & \\
\hline \multirow{2}{*}{$\begin{array}{l}\text { PIB per capita } 2 \\
(75,333)\end{array}$} & $-525,070^{(a)}$ & $-519,651^{(a)}$ & $-478,104^{(a)}$ & $-528,551^{(a)}$ & $-460,190^{(a)}$ & $-497,058^{(a)}$ \\
\hline & $(74,620)$ & $(75,271)$ & $(78,083)$ & $(39,773)$ & $(41,068)$ & \\
\hline \multirow{2}{*}{$\begin{array}{l}\text { PIB per capita } \\
(529,629)\end{array}$} & $2.792,592^{(a)}$ & $2.766,093^{(a)}$ & $2.625,225^{(a)}$ & $2.828,810^{(a)}$ & $2.623,265^{(a)}$ & $2.858,801^{(a)}$ \\
\hline & $(525,122)$ & $(525,237)$ & $(550,595)$ & $(283,556)$ & $(291,813)$ & \\
\hline Dummy 2010 & Sim & Sim & Sim & Sim & Sim & Sim \\
\hline Covariadas & Sim & $\operatorname{Sim}$ & $\operatorname{Sim}$ & $\operatorname{Sim}$ & $\operatorname{Sim}$ & $\operatorname{Sim}$ \\
\hline Prob $>$ F & 0,000 & 0,000 & 0,000 & 0,000 & -- & -- \\
\hline Prob $>$ chi $^{2}$ & -- & -- & -- & --- & 0,000 & 0,000 \\
\hline $\begin{array}{l}\text { Teste de } \\
\text { Hausman }\end{array}$ & $193,94^{(a)}$ & $200,75^{\text {(a) }}$ & $196,16^{(a)}$ & $193,94^{(a)}$ & --- & --- \\
\hline Observações & 11.069 & 11.069 & 11.069 & 11.069 & 11.069 & 11.069 \\
\hline \multirow{2}{*}{ Turning points } & 0,231 & 0,225 & --- & 0,186 & -- & --- \\
\hline & 0,183 & -- & 0,186 & 0,126 & --- & -- \\
\hline
\end{tabular}

Fonte: Elaboração própria a partir de PNUD (INSTITUTO DE PESQUISA ECONÔMICA APLICADA, 2013) e IBGE $(2010,2000)$

Notas: Erros padrões robustos entre parênteses; ${ }^{\left({ }^{a}\right)}$ significativo a $1 \%$, ${ }^{(b)}$ significativo a $5 \%$ e ${ }^{\text {(c) }}$ significativo a $10 \%$. 
Pelo lado do emprego, os resultados também são favoráveis à relação entre desigualdade de rendimentos do trabalho e industrialização em $U$ invertido. Os coeficientes associados à função quadrática da variável "emprego indústria", em todas as estimações em que é considerada, são significativos, positivos em nível e negativos ao quadrado. Ademais, os coeficientes para a variável ao cubo não são significativos (especificação IV). Esses resultados são observados por efeitos fixos e por tobit em painel. Assim, a desigualdade dos rendimentos do trabalho aumenta devido à industrialização até dada participação industrial no emprego (turning point), a partir da qual cai. Na especificação I, o turning point ( $\overline{E I})$ é, em uma participação industrial média no emprego, de 18,3\%; na III, o turning point é de 18,6\%; e, na IV, o turning point é de $12,6 \%$.

As participações médias da indústria no produto e no emprego, em 2010, nos municípios brasileiros eram de 16\% e 16,7\%, respectivamente (ver Tabela 1). Essas participações são inferiores aos respectivos turning points em todas as estimações. Assim, pode-se inferir que processos de industrialização nos municípios, com aumento da participação no produto e no emprego, ceteris paribus, tenderão a aumentar, inicialmente, a desigualdade dos rendimentos do trabalho. Porém, à medida que tais processos se aprofundarem, os turning points serão atingidos e a desigualdade passará a cair. Comparando-se os turning points calculados do VA $(\overline{V I})$ e do emprego $(\overline{E I})$, pode-se afirmar que a redução da desigualdade ocorre antes com o avanço do emprego industrial.

Em relação aos coeficientes estimados associados à função cúbica do PIB per capita, a hipótese da CK (relação desigualdade-renda em $U$ invertido) não é corroborada em todas as estimações. Os coeficientes associados ao PIB per capita são significativos, positivos em nível e negativos ao quadrado, como preconiza a hipótese. Porém, os coeficientes associados ao PIB per capita ao cubo são significativos e positivos, o que sinaliza que a relação desigualdade-crescimento tem formato próximo a um $N$. Os testes da segunda derivada confirmam tal formato. ${ }^{7}$

Por último, a Figura 1 apresenta as relações ajustadas pelo método de regressão não paramétrica kernel-weighted local polynomial regression. O gráfico $a$ mostra a relação entre a desigualdade de renda (Theil- $L$ trabalho) - eixo vertical - e a participação industrial no emprego (emprego indústria) - eixo horizontal. Observa-se que a desigualdade aumenta até certo nível de participação industrial, a partir do qual diminui, o que se configura como outra evidência para corroborar a relação em $U$ invertido sugerida pelas estimações paramétricas. Já na participação industrial no produto (VA indústria), o gráfico b sinaliza que, com oscilações, a desigualdade dos rendimentos do trabalho (Theil- $L$ trabalho) - eixo vertical aumenta até certo estágio de participação industrial - eixo horizontal -, a partir do qual passa a diminuir. Pode-se questionar que existe uma aparente reversão da

7 Os testes e os pontos críticos não são reportados, mas podem ser obtidos junto aos autores. 
tendência de queda em níveis mais avançados de participação industrial no produto. Porém, vale ressalvar que a desigualdade de renda não atinge um patamar similar ao observado em níveis intermediários de participação, o que não permite refutar integralmente a hipótese da relação desigualdade-industrialização em $U$ invertido, ainda mais por ter sido sinalizada em todas as estimações paramétricas.

Figura 1 - Relações ajustadas entre a desigualdade de rendimentos e as participações industriais no emprego (a) e no produto (b) (2010)

(a) Participação no Emprego

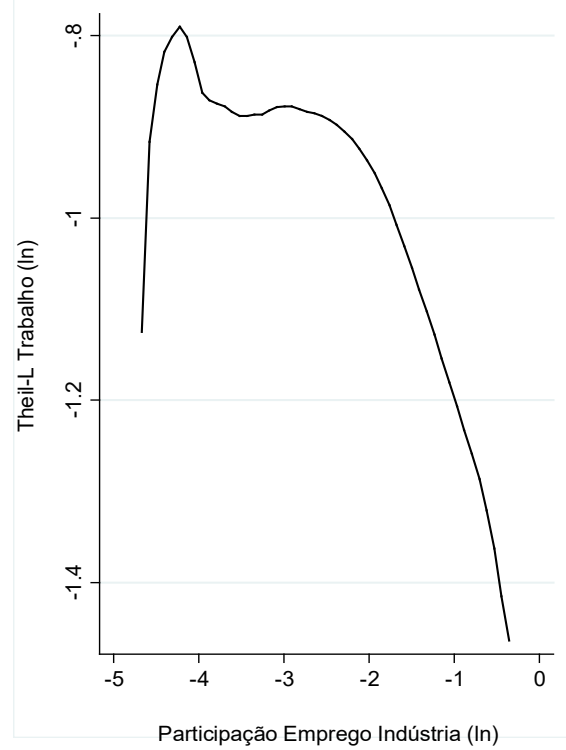

(b) Participação no Produto

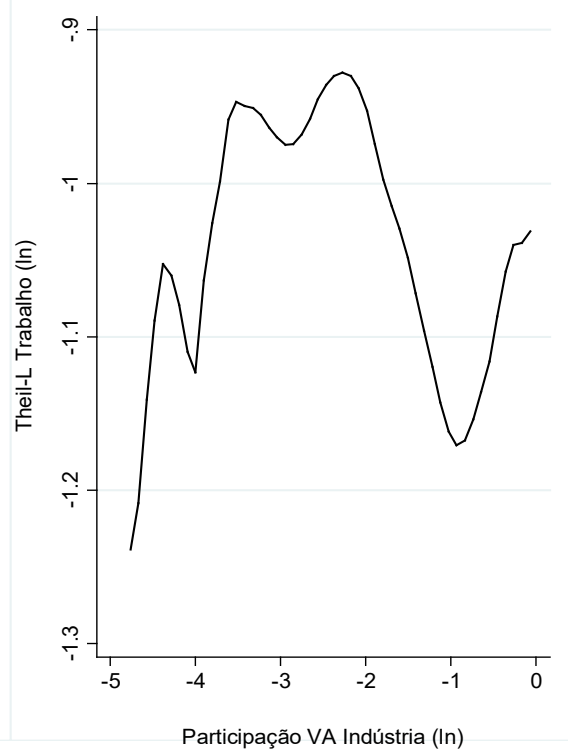

Fonte: Elaboração própria a partir de PNUD (INSTITUTO DE PESQUISA ECONÔMICA APLICADA, 2013) e IBGE $(2010,2000)$

\section{Considerações Finais}

A distribuição da renda e a industrialização são temas recorrentes e de suma importância ao desenvolvimento econômico. Discussões da academia brasileira e em âmbito mundial, sistematizadas no início deste estudo, tentam explicar as interações dessas duas dimensões. Uma das vertentes que pode ser destacada é a da economia dual, que defende a dinâmica da composição setorial de uma economia como condicionante da desigualdade. Para ela, em uma primeira fase, a transição de uma economia baseada em atividades de agropecuária para uma predo- 
minantemente industrial - ou seja, um processo de industrialização - elevaria a desigualdade de renda. Porém, uma vez consolidada a indústria, a desigualdade cairia. Em uma segunda fase, a transição da economia industrial para uma baseada em serviços - que pode representar um processo de desindustrialização natural - geraria novo aumento da desigualdade. Assim, a industrialização, tanto para a agropecuária quanto para o setor de serviços, melhoraria a distribuição de renda.

Tal hipótese foi testada e corroborada neste estudo por meio de estimações econométricas paramétricas em painel (efeitos fixos e efeitos aleatórios) e não paramétricas (kernel-weighted local polynomial regression) para todos os municípios brasileiros com informações referentes aos anos de 2000 e 2010 . Utilizando-se como medida de desigualdade o Theil- $L$ dos rendimentos do trabalho, constatou-se que a desigualdade aumenta em função da industrialização até certa participação da indústria, a partir da qual passa a cair. Tal relação foi observada tanto para a participação industrial no produto quanto no emprego. Portanto, as evidências sinalizam, com certa robustez, que a relação desigualdade-industrialização tem, nos municípios brasileiros, um formato próximo a um $U$ invertido. Adicionalmente, observou-se que a relação entre a desigualdade dos rendimentos e o crescimento econômico nos municípios apresenta um formato próximo a um $N$, contestando a hipótese da CK.

Esses resultados, além de contribuírem para o preenchimento de uma lacuna na literatura empírica para dados de munícipios brasileiros, garantem evidências adicionais à literatura que tentam explicar a complexa cadeia causal entre o processo de industrialização, a desigualdade de renda e o crescimento/desenvolvimento econômico. Vale ressalvar que o estudo se preocupou em garantir evidências ainda inéditas que podem motivar trabalhos futuros mais aprofundados, que considerem, além da participação setorial, por exemplo, a especialização, a complexidade tecnológica, a intensidade de trabalho e a produtividade em cada setor e suas interações com outros setores, como as agroindustriais e atividades de serviços que atendam as indústrias.

\section{Referências}

AGHION, P.; BOLTON, P. Distribution and growth in models of imperfect capital markets. European Economic Review, v. 36, n. 2-3, p. 603-611, Apr. 1992.

AHLUWALIA, M. S. Income distribution and development: some stylized facts. The American Economic Review, v. 66, n. 2, p. 128-135, May 1976.

ALVAREZ, A. R. Desenvolvimentos teóricos sobre distribuição de renda com ênfase em seus limites. 1996. Dissertação (Mestrado) - Universidade de São Paulo, São Paulo, 1995. 
ANAND, S.; KANBUR, S. M. R. The Kuznets process and the inequality-development relationship. Journal of Development Economics, v. 40, n. 1, p. 25-52, 1993.

BACHA, E. L. Hierarquia e remuneração gerencial. In: TOLIPAN, R.; TINELLI, A. C. (coord.). A controvérsia sobre a distribuição de renda e desenvolvimento. Rio de Janeiro: Zahar, 1978.

BACHA, E. L.; TAYLOR, L. Brazilian income distribution in the 1960s: acts, model results, and the controversy. In: TAYLOR, L.; BACHA, E. L.; CARDOSO, E. A.; LYSY, F. J. (ed.). Models of growth and distribution for Brazil. Oxford: Oxford University Press, 1980.

BAER, M. O rumo perdido: a crise fiscal e financeira do Estado brasileiro. Rio de Janeiro: Paz e Terra, 1993.

BALTAGI, B. H. Econometric analysis of panel data. New York: Wiley and Sons, 2001.

BARROS, R. P.; FOGUEL, M. N.; ULYSSEA, G. (org.). Desigualdade de renda no Brasil: uma análise da queda recente (volumes 1 e 2). Brasília: IPEA, 2007.

BARROS, R. P.; HENRIQUES, R.; MENDONCA, R. Pelo fim das décadas perdidas: educação e desenvolvimento sustentado no Brasil. In: HENRIQUES, R. (org.). Desigualdade e pobreza no Brasil. Brasília: IPEA, 2000.

BELLUZZO, W.; ANUATTI NETO, F.; PAZELLO, E. T. Distribuição de salários e o diferencial público-privado no Brasil. Revista Brasileira de Economia, v. 59, n. 4, p. 511-533, 2005.

BÊRNI, D. A.; MARQUETTI, A.; KLOECKNER, R. A desigualdade econômica no Rio Grande do Sul: primeiras investigações sobre a curva de Kuznets. Ensaios FEE, v. 23, p. 443-466, 2002.

BISHOP, J. A.; FORMBY, J. P.; THISTLE, P. D. Changes in the US earnings distributions in the 1980s. Applied Economics, v. 23, n. 3, p. 425-433, 1991.

BONELLI. R.; RAMOS. L. Distribuição de renda no Brasil: avaliação das tendências de longo prazo e mudanças na desigualdade desde meados dos anos 70. Texto para discussão, n. 288, Brasília: IPEA, 1993.

CANO, W. Desequilíbrios regionais e concentração industrial no Brasil - 1930/1970. 1981. Tese (Livre-Docência) - Universidade Estadual de Campinas, 1981.

CANO, W. Concentração e desconcentração econômica regional no Brasil. Economia e Sociedade, Campinas, v. 6, n. 1, p. 101-141, 1997.

CARDOSO, J. C.; POCHMANN, M. Raízes da concentração de renda no Brasil: 1930 a 2000. Brasília: IPEA/CESIT, 2000. Mimeo.

CARNEIRO, D. D. Crise e esperança: 1974-1980. In: RESENDE, A. L.; CARNEIRO, D. D.; MODIANO, E. M.; ABREU, M. P. (org.). A ordem do progresso. 15. ed. Rio de Janeiro: Campus, 1990.

CHIANG, A. Matemática para economistas. São Paulo: McGraw-Hill, 1982. 
CLARK, C. The conditions of economic progress. London: Macmillan, 1957.

CLEVELAND, W.; DEVLIN, S. Locally weighted regression: an approach to regression analysis by local fitting. Journal of the American Statistical Association, v. 83, n. 403, p. 596-610, Sept. 1988.

DEDECCA. C. S. A redução da desigualdade e seus desafios. Brasília: IPEA, 2015. (Textos para discussão do IPEA, n. 2031)

DEUTSCH, J.; SILBER, J. The Kuznets curve and the impact of various income sources on the link between inequality and development. Working Paper, Bar-Ilan University, Israel, 2000 .

FISHLOW, A. Brazilian size distribution of income. American Economic Review, v. 62, n. 1/2, p. 391-402, Mar. 1972.

FISHLOW, A. A distribuição de renda no Brasil. In: TOLIPAN, R.; TINELLI, A. C. (coord.). A controvérsia sobre a distribuição de renda e desenvolvimento. Rio de Janeiro: Zahar, 1978.

FONSECA, P. C. D. Sobre a intencionalidade da política industrializante do Brasil na década de 1930. Brazilian Journal of Political Economy, São Paulo, v.23, n. 1, p. 138-153, jan./mar. 2003.

FURTADO, C. Formação econômica do Brasil. 7. ed. São Paulo: Ed. Nacional, 1967.

GALOR, O.; TSIDDON, D. Income distribution and growth: the Kuznets hypothesis revisited. Economica, v. 63, n. 250, p. 103-117, 1996.

GANDRA, R. O debate sobre a desigualdade de renda no Brasil: da controvérsia dos anos 70 ao pensamento hegemônico nos anos 90. História Econômica 83 História de Empresas, v. 8, n. 1, p. 139-162, 2005.

GLAESER, E. L. Inequality. NBER Working Paper Series, Cambridge, n. 11511, jun. 2005.

GREENE, W. H. Econometric analysis. 7. ed. Boston: Prentice Hall, 2011.

HALLAK NETO, J.; SABOIA, J. Distribuição funcional da renda no brasil: análise dos resultados recentes e estimação da conta da renda. Economia Aplicada, Ribeirão Preto, v. 18, n. 3, p. 483-513, jul./set. 2014.

HOFFMANN, R. Distribuição da renda agrícola e sua contribuição para a desigualdade de renda no Brasil. Revista de Política Agrícola, v. 20, n. 2, p. 5-22, 2011.

HOFFMANN, R.; DUARTE, J. C. A distribuição da renda no Brasil. Revista de Administração de Empresas, v. 12, n. 2, p. 46-66, 1972.

HOFFMANN, R.; NEY, M. G. A recente queda da desigualdade de renda no Brasil: análise de dados da PNAD, do Censo Demográfico e das Contas Nacionais. Econômica, v. 10, n. 1, p. 7-39, 2008. 
INSTITUTO BRASILEIRO DE GEOGRAFIA E ESTATÍSTICA. Censo demográfico de 2010. IBGE, 2010. Disponível em: https://censo2010.ibge.gov.br. Acesso em: 22 mar. 2017.

INSTITUTO BRASILEIRO DE GEOGRAFIA E ESTATÍSTICA. Censo demográfico de 2000. IBGE, 2000. Disponível em: https://www.ibge.gov.br/censo/divulgacao.shtm. Acesso em: 12 mar. 2017.

INSTITUTO DE PESQUISA ECONÔMICA APLICADA. Atlas do desenvolvimento humano no Brasil. Brasília: PNUD, 2013. Disponível em: http://www.atlasbrasil.org.br/. Acesso em: 22 mar. 2017.

INSTITUTO DE PESQUISA ECONÔMICA APLICADA. Distribuição funcional da renda pré e pós crise internacional no Brasil. Comunicados do IPEA, n. 47, maio 2010.

JHA, S. K. The Kuznets Curve: a reassessment. World Development, v. 24, n. 4, p. 773-780, 1996.

JONES, M. C.; DAVIES, S. J.; PARK, B. U. Versions of Kernel-type regression estimators. Journal of the American Statistical Association, v. 89, n. 427, p. 825-832, 1994.

KALDOR, N. Causes of the slow rate of economic growth of the United Kingdom: an inaugural lecture. Cambridge: Cambridge University Press, 1966.

KATZ, L.; MURPHY, K. Changes in relative wages, 1963-1987: supply and demand factors. The Quarterly Journal of Economics, v. 107, n.1, p. 35-78, 1992.

KUZNETS, S. Economic growth and income inequality. The American Economic Review, v. 45, n. 1, p. 1-28. 1955.

LAGO, L. A. C. A retomada do crescimento e as distorções do "Milagre": 1967-1973. In: RESENDE, A. L; CARNEIRO, D. D.; MODIANO, E. M.; ABREU, M. P. (org.). A ordem do progresso. 15. ed. Rio de Janeiro: Campus, 1990. p. 233-295.

LANGONI, C. G. Distribuição da renda e desenvolvimento econômico do Brasil: uma reafirmação. Ensaios Econômicos EPGE, n. 8, Rio de Janeiro, 1973.

LEWIS, W. A. Economic development with unlimited supplies of labor. Manchester School of Economics and Social Studies, v. 22, n. 2, p. 139-191, 1954.

LIST, J. A.; GALLET, C. A. The Kuznets curve: what happens after the inverted-U. Review of Development Economics, v. 3, n. 2, p. 200-206, 1999.

LOADER, C. Local regression and likelihood. New York: Springer, 1999.

MAIA. A. G. Estrutura de ocupações e distribuição de rendimentos: uma análise da experiência brasileira nos anos 2000. Revista de Economia Contemporânea, Rio de Janeiro, v. 17, n. 2, p. 276-301, ago. 2013.

MARCONI, N. Uma breve comparação entre os mercados de trabalho do setor público e privado. Revista do Serviço Público, Brasília, v. 48, n. 1, p. 126-146, mar. 1997. 
MELLO, J. M. C. O capitalismo tardio: contribuição à revisão crítica da formação e do desenvolvimento da economia brasileira. São Paulo: Brasiliense, 1986.

MINCER, J. Schooling, experience, and earnings. New York: Columbia University Press, 1974.

NAKAHODO, S. N.; JANK, M. S. A falácia da doença holandesa. São Paulo: Instituto de Estudos do Comércio e Negociações Internacionais, 2006.

OLIVEIRA, R.; SILVEIRA NETO, R. M. Estrutura produtiva ou escolaridade? Uma análise dos fatores explicativos da desigualdade de renda entre as regiões Sudeste e Nordeste por quantil para o período entre os anos de 1970 e 2010. Revista Econômica do Nordeste, Fortaleza, v.47, n.3, p. 75-91, set. 2016.

OREIRO, J. L.; FEIJÓ, C. A. Desindustrialização: conceituação, causas, efeitos e o caso brasileiro. Brazilian Journal of Political Economy, v. 30, n. 2, p. 219-232, jun. 2010.

PIKETTY, T. The Kuznets Curve: yesterday and tomorrow. In: BANERJEE, A.; BENABOU, R.; MOOKHERJEE, D. (ed.). Understanding poverty. Oxford: Oxford Press, 2006.

PREBISCH, R. O desenvolvimento econômico da América Latina e alguns de seus problemas principais. Boletín económico de América Latina, CEPAL, v. 7, n. 1, 1962.

RAMOS, L. Desigualdade de renda e crescimento econômico no Brasil: 1976/85. Brasília: IPEA, 1991. (Textos para Discussão do IPEA, n. 213)

ROCHA, L. E. V.; SANTOS, G. C.; ROSADO, P. L. Indicadores de desigualdade de renda e pobreza na agricultura do Estado de Minas Gerais. Organizações Rurais $\mathcal{E}$ Agroindustriais, Lavras, v.15, n.3, p. 425-442, set. 2013.

ROWTHORN, R.; RAMASWAMY, R. Deindustrialization: causes and implications. Working Paper, International Monetary Fund, n. 97, v. 42, 1997.

ROWTHORN, R; WELLS, J. R. De-industrialization and foreign trade. Cambridge: Cambridge University Press, 1987.

SABOIA, J. Descentralização industrial no Brasil na década de noventa: um processo dinâmico e diferenciado regionalmente. Nova Economia, Belo Horizonte, v. 11, n. 2, p. 85-122, dez. 2001.

SILVA, H. C. M. Deterioração dos termos de intercâmbio, substituição de importações, industrialização e substituição de exportações: a política de comércio exterior brasileira de 1945 a 1979. Revista Brasileira de Política Internacional, Brasília, v. 46, n. 1, p. 39-65, jun. 2003.

SOARES, S. S. D. Distribuição de renda no Brasil de 1976 a 2004 com ênfase no período entre 2001 e 2004. Brasília, 2006. (Textos para Discussão do IPEA, n. 1166)

TAVARES, M. C. Da substituição de importações ao capitalismo financeiro: ensaios sobre economia brasileira. 4. ed. Rio de Janeiro: Zahar, 1975. 
TREGENNA, F. Characterizing deindustrialization: an analysis of changes in manufacturing employment and output internationally. Cambridge Journal of Economics, Cambridge, v. 33, n. 3, p. 433-466, May 2009.

\section{Autor correspondente:}

Bruno Benzaquen Perosa

Recebido em: 15/06/2018.

E-mail: brperosa@ufu.br

Aceito em: 02/09/2019.

\section{(cc) BY}

Este é um artigo de acesso aberto distribuído sob os termos da Creative Commons

Attribution CC-BY 4.0, que permite uso irrestrito, distribuição e reprodução em

qualquer meio, desde que o trabalho original seja devidamente citado. 